\title{
MORFOPEDOLOGIA E ZONEAMENTO VOLTADO À OCUPAÇÃO
}

\author{
Fernando Nadal Junqueira Villela ${ }^{1}$ \\ Sidneide Manfredini ${ }^{2}$ \\ Aparecida Juliana Martins Corrêa ${ }^{3}$ \\ Janaína Braga do Carmo ${ }^{4}$
}

RESUMO: $O$ planejamento $e$ adequada gestão dos recursos naturais requer $o$ reconhecimento dos componentes da paisagem e das relações estruturais e funcionais que se estabelecem entre eles. Procedeu-se à confecção de uma carta morfopedológica do campus universitário da UFSCar no município de Sorocaba, Estado de São Paulo, como base para a definição de um zoneamento da aptidão do meio físico ao uso e à ocupação. $A$ compartimentação morfopedológica relaciona satisfatoriamente as formas de relevo e os solos por meio de uma série de documentos cartográficos analisados de modo integrado (referentes à pedologia, à geologia, à morfologia, à declividade e à hipsometria) e da associação decorrente das análises empíricas e laboratoriais do solo. Tais análises possibilitaram a compreensão das inter-relações existentes entre os diferentes componentes da paisagem, proporcionando a definição dos compartimentos morfopedológicos utilizados para o zoneamento realizado. Este se constitui em um instrumento de diagnóstico $e$ prognóstico essenciais ao planejamento e à gestão, com vistas à conservação da paisagem.

Palavras-chave: análise morfopedológica, solos, Campus UFSCar-Sorocaba, zoneamento.

\section{MORPHOPEDOLOGY AND ZONING FOR OCCUPATION}

ABSTRACT: The recognition of the landscape components and the structural and functional relations established among them are fundamental requirements for proper planning and management of the natural resources. A morphopedological map of the area of the UFSCar campus, in the municipality of Sorocaba, Brazil, was created, as the basis for the physical zoning of the physical landscape's aptitude to human usage and occupation. The morphopedological compartmentation relates, satisfactorily, landforms and soils through the integrated analysis of a series of cartographic documents (pedology, geology, morphology, slope and hypsometry) and the association of the data generated by empiric testing and laboratorial analysis of the soils. Such analysis led to an understanding of the interrelations between the different components of the landscape, allowing for the definition of the morphopedological compartments used in the physical zoning process, which constitutes, itself, an instrument for diagnosis and prognosis, essential for planning and management, aiming, ultimately in the preservation of the landscape.

Keywords: Morphopedological analysis, soils, UFSCar Sorocaba campus, zoning

1. Departamento de Geografia / Universidade de São Paulo (geovillela@usp.br).

2. Departamento de Geografia / Universidade de São Paulo (sidmanfredini@gmail.com).

3. Universidade Federal de São Carlos (jumartinscorrea@gmail.com).

4. Universidade Federal de São Carlos (jbcarmo@gmail.com). 


\section{INTRODUÇÃO}

Planejamentos visando a conservação dos recursos naturais necessitam de levantamentos específicos que contemplem a paisagem ou ambiente envolvidos. Geralmente, zoneamentos voltados ao uso e ocupação utilizam bases de dados cujas escalas de trabalho não permitem o reconhecimento em detalhe dos diversos fatores que compõe o meio físico, sem haver análise condizente com a realidade de campo. Como é o caso de muitas áreas no Estado paulista, a região de Sorocaba carece de dados sistemáticos de maior detalhe que contemplem suas características naturais e que possam ser aproveitados no planejamento e gestão direcionados à ocupação do território.

O município de Sorocaba situa-se na Depressão Periférica Paulista, na borda leste da Bacia Sedimentar do Paraná, e abrange também porções do Planalto Atlântico (Ross e Moroz, 1997). Por localizar-se na transição de uma área serrana sustentada por rochas cristalinas do embasamento para uma depressão recoberta por rochas sedimentares, o modelado de relevo é caracterizado por morrotes de encostas mais íngremes (área cristalina) para colinas de topografia mais suave (área sedimentar). Solos vermelhos e profundos desenvolvem-se no modelado colinoso, sob ação do clima alternadamente quente e chuvoso no verão e moderado e seco no inverno. A vegetação, embora muito alterada, ainda possui alguns fragmentos de fitofisionomias de cerrado, com indivíduos arbustivos de aspecto lenhoso, além de outras de maior porte, correspondentes a espécies da mata atlântica.

Ao longo da Rodovia João Leme dos Santos (SP-264), que liga o município de Sorocaba ao de Salto de Pirapora, verifica-se um intenso fluxo de transporte de mercadorias. A implantação do campus da Universidade Federal de São Carlos (UFSCar), assentado sobre um interflúvio aplainado, tem estimulado a implantação de inúmeros condomínios que induzem, por sua vez, a expansão do setor terciário, intensificando o processo de urbanização. Soma-se a esse processo a própria população universitária flutuante, que demanda, com os habitantes, a utilização de água, esgotos, vias pavimentadas, alojamentos, etc. Esse cenário torna necessário planejamento e organização do território, a fim de compatibilizar as necessidades humanas com as características naturais existentes.

Portanto, o objetivo central deste trabalho é a construção de um produto cartográfico que possibilite o diagnóstico preliminar do meio físico existente na área do campus universitário e em seu entorno, por meio da relação entre rocha, solo e relevo. A análise de mapas temáticos e análises de campo, gabinete e laboratório tornam possível a compreensão desses fatores associados, resultando em uma compartimentação morfopedológica. Com o mapa morfopedológico confeccionado, é possível, então, direcionar total, moderada ou restritamente as áreas referentes à ocupação antrópica, integrada aos fatores supracitados por meio de zoneamento.

\section{MATERIAL E MÉTODO}

O estudo das paisagens engloba processos estruturais e esculturais das formas de relevo e fatores formadores dos solos, sendo central para o entendimento da superfície do ponto de vista morfopedológico. O procedimento básico para a compreensão da conexão entre os 
componentes abióticos da paisagem é a compartimentação do meio físico, que leva em conta as inter-relações entre o substrato geológico, o modelado de relevo e os solos.

A metodologia morfopedológica partiu das abordagens de Tricart e Kilian (1982) e foi aprimorada, no Brasil, por Castro e Salomão (2000). Sua investigação coteja as demandas de uso racional da terra pela intervenção humana associada ao entendimento físico do ambiente envolvido. Nessa linha de investigação se definem as bases desse tipo de pesquisa: identificação das fisionomias e apreensão das estruturas, das funcionalidades dinâmicas e da suscetibilidade para as intervenções humanas. O levantamento morfopedológico, dessa maneira, associa-se ao planejamento, com consequente zoneamento para uso e ocupação antrópica, a fim de estabelecer diretrizes e limitações à organização do território que respeitem as condições naturais.

A área de estudo localiza-se no sudeste do Estado de São Paulo, Brasil, entre as latitudes 23을 $34^{\prime} 37^{\prime \prime}$ a 23 $35^{\prime} 20^{\prime \prime}$ S e longitudes 470 30' 52" a 470 31' 51" W. Corresponde, como já indicado, ao campus universitário da Universidade Federal de São Carlos, e possui área aproximada de 70 ha, situando-se no município de Sorocaba próximo ao limite com o município de Salto de Pirapora.

No tocante aos materiais, foram confeccionadas uma carta de hipsometria, fundamentada em Libault (1975), e outra de declividades, embasada em De Biasi (1992). Ademais, foi composta uma carta morfológica, com a utilização de fotografias aéreas em escala 1:25.000 (Base Aerofotogrametria e Projetos S. A, 1962 a, b), e uma carta geológica, cuja legenda associou-se aos levantamentos de Almeida et al. (1981), Godoy (1989) e Silva (1997), com atualizações de campo. Houve também a elaboração de um mapa pedológico, baseado em levantamentos de campo (análises morfológicas de três perfis de solo) e análises de laboratório (granulometria, relações texturais e fertilidade), e de um mapa morfopedológico, que correspondeu a uma síntese dos mapas morfológico, geológico e pedológico. Todos foram ajustados à base cartográfica em escala 1:10.000 (IGC, $1979 \mathrm{a}, \mathrm{b}$ ).

Também foram desenvolvidos mapas de uso da terra a partir das fotografias aéreas, da base cartográfica e do Google Earth, com controle de campo. Por fim, a carta de zoneamento foi relacionada às cartas do esboço morfopedológico e do uso da terra, considerando as subdivisões associadas às cartas de hipsometria, declividades e morfologia, o que gerou a carta de zoneamento de aptidão ao uso e à ocupação da área de estudo.

A coleta de amostras de solo acompanhou as análises morfológicas de perfis em três trincheiras abertas na área do campus, cuja descrição adequou-se aos procedimentos relatados em Santos et al. (2013). Foram realizadas análises granulométricas com limites de frações estabelecidos pelo IBGE (2007), ao passo que as análises de fertilidade do solo (atentando para $\mathrm{pH}$, matéria orgânica, P-resina, $\mathrm{K}, \mathrm{Ca}, \mathrm{Fe}, \mathrm{Mg}, \mathrm{H}+\mathrm{Al}$ e cálculos de SB, T e V\%) também foram determinadas pelos critérios de Santos et al. (2013). Os resultados analíticos foram confrontados com os atributos diagnósticos estabelecidos pelo SiBCS - Sistema Brasileiro de Classificação dos Solos (Santos et al., 2013) na definição da tipologia da cobertura pedológica.

Além disso, foram definidos pontos de amostragem confirmatórios da distribuição espacial das manchas homogêneas de solos. Nesses pontos, foram coletadas amostras por tradagem, 
de 10 em $10 \mathrm{~cm}$, nas quais foram analisadas cor (Munsell), granulometria, relação silte/argila e V\% (saturação em bases).

\section{RESULTADOS}

O terreno da área de estudo corresponde a uma colina com vertentes em sua maioria suaves, assentadas entre duas cabeceiras de drenagem, cujas águas correm para o Córrego Utinga. É, portanto, região de nascente, ainda que com baixa densidade de drenagem, amplitudes topográficas de apenas $50 \mathrm{~m}$ e modelado de relevo pouco variado. Os níveis hipsométricos são pouco diferenciados, embora existam alguns setores mais íngremes, indicados pelas declividades associadas a outros elementos do meio físico (Figura 01).

Os topos mais amplos e suavizados dos interflúvios são sustentados por litologias sedimentares (siltitos e arenitos), e os aplainamentos mais evoluídos promovem o aparecimento de uma superfície extensa, que define uma área contínua de topos aplainados. Em direção aos fundos de vale, passando para setores de vertente amplos a dissecados, há transição para substrato cristalino (rochas ígneas ou metamórficas), o que configura vertentes de maior declividade. Os vales fluviais possuem limites bem definidos, com anfiteatros em alvéolos nas cabeceiras que se estreitam em direção à jusante, cortando as litologias sedimentares e cristalinas ao longo de suas delimitações. A planície fluvial também se mostra bem demarcada, diferenciando-se das morfologias restantes por seu fundo plano e por seu preenchimento por depósitos aluvionares.

As litologias sedimentares e cristalinas - aliadas ao clima tropical, alternadamente seco e úmido - conferem aos solos da área, desenvolvimento pedológico diverso. Tal variação também é determinada em razão das declividades, sobretudo, da área de topo aplainado aos setores de vertente amplos a dissecados. De forma geral, nos topos que correspondem às altitudes de 640 a $660 \mathrm{~m}$, há associações de Latossolos de textura argilosa, de horizonte $A$ moderado. Nos relevos de maior declividade, com altitudes entre 640 e $620 \mathrm{~m}$, surgem solos rasos (Cambissolos) de textura por vezes argilosa, com horizonte Bi evoluindo para uma organização latossólica. Nos terrenos mais baixos e planos, onde se encontra a planície fluvial restrita, ocorrem Gleissolos.

A cobertura vegetal é caracterizada por fragmentos remanescentes de cerrado (IPT, 2006). A utilização intensa da terra para a agricultura gerou uma série de fitofisionomias secundárias e espécies exóticas, que invadiram áreas desmatadas e possuem porte atual variável. Ademais, ainda conservadas, existem algumas matas ciliares, dominadas por árvores com alta densidade de indivíduos e copas fechadas nos estratos superiores, com ervas e arbustos nos níveis inferiores. A vegetação da planície fluvial, por sua vez, é de composição variável, muito alterada pela ocupação humana.

Por meio dos mapas de uso da terra (Figura 01 já mostrada), pode-se observar que a ocupação apresenta diferenças de sua fase como propriedade rural, com cultivo de eucalipto e áreas de pastagem (década de 1960), para sua definição como campus universitário, ocorrida a partir de 2006. 


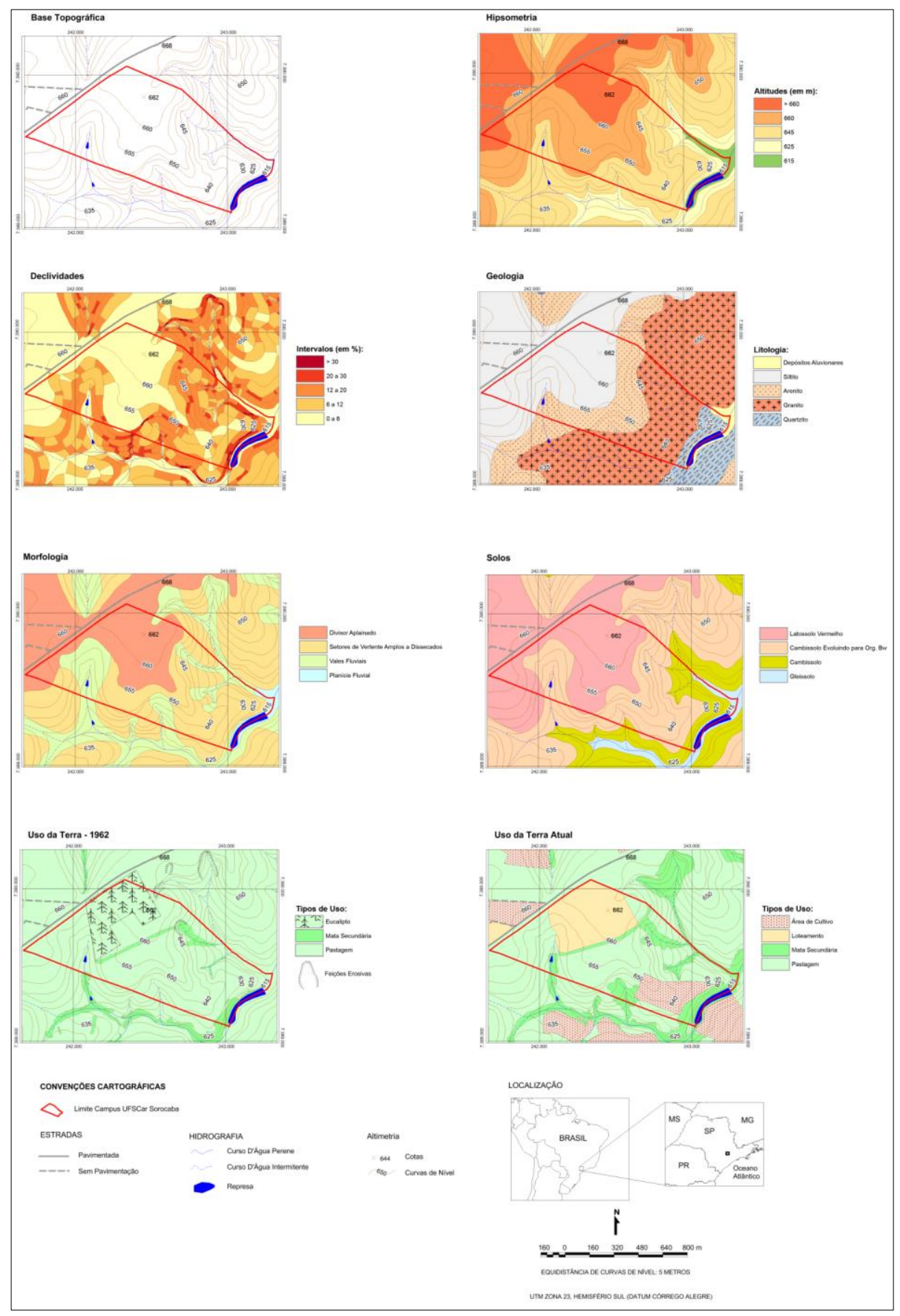

FIGURA 01: Localização e mapeamentos da área de estudo.

Com isso, o terreno mais plano passou a ser preferencialmente ocupado pelas edificações, cujo entorno ainda é caracterizado por culturas anuais, além das pastagens. Nota-se, igualmente, que, desde a década de 1960, há uma recuperação progressiva das matas secundárias que envolvem as cabeceiras de drenagem.

Verifica-se que na área contínua de topos aplainados, no terço superior das vertentes (Trincheira 1 e pontos 1 e 14, Figura 02 e Tabela 01), quando sustentados por litologia sedimentar (siltitos argilosos), os solos possuem textura franco-argilosa e relação silte/argila próxima do condizente com o atributo diagnóstico de horizonte $B$ latossólico - Bw, menor que 0,6 segundo Santos et al. (2013). Esse Latossolo apresenta cores vermelhas, no matiz 2.5 
YR, e possui caráter que varia de levemente eutrófico a distrófico. Segundo relatos de obras locais para canalização de esgotos e águas pluviais, seu desenvolvimento pode ultrapassar $10 \mathrm{~m}$ de profundidade.

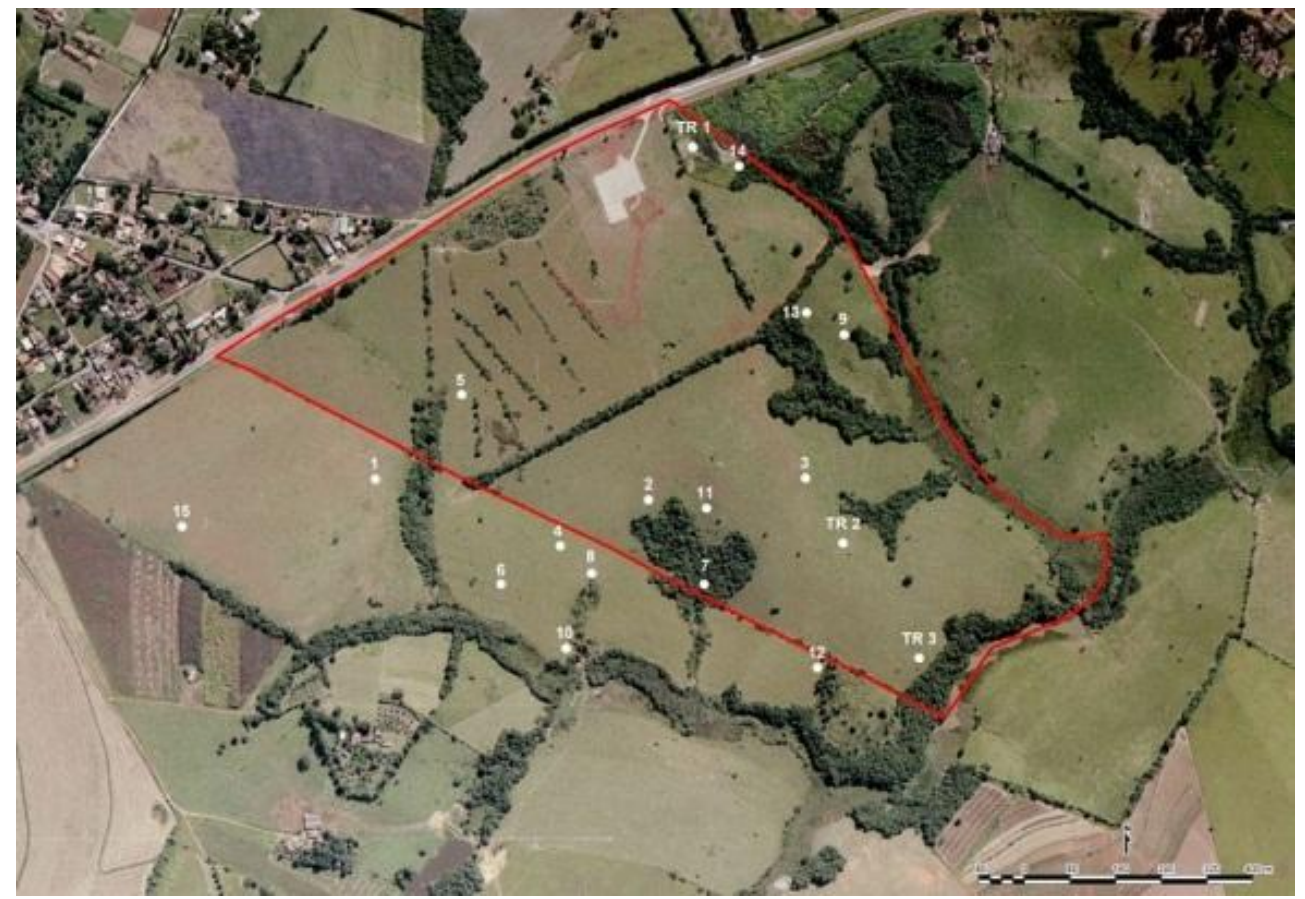

FIGURA 02: Localização dos pontos de coleta de amostras de solo e trincheiras. Legenda: TR = Trincheira; indicação dos perfis de solo: TR 1 = Latossolo Vermelho, TR 2 = Cambissolo evoluindo para organização de horizonte Bw, TR 3 = Cambissolo; área do campus UFSCar-Sorocaba em vermelho.

Fonte: Aerocarta S. A. (2006).

Os Latossolos Vermelhos correspondem ao exemplo da mancha contínua que configura essas áreas de patamares planos do divisor topográfico principal, onde passa a Rodovia João Leme dos Santos sobre o principal espigão da região mapeada. Ao haver transição sutil da área contínua de topos aplainados para setores de vertente amplos a dissecados, no terço médio, com mudança da litologia de siltitos para arenitos ou mesmo para litologia cristalina, esses Latossolos Vermelhos dão lugar aos Cambissolos, cujas condições levemente eutróficas e grau de intemperismo, além de evidências morfológicas (espessamento do horizonte B), indicam evolução da organização para horizonte Bw (latossólico). Portanto, os pontos 2, 3, 4, 5, 6, 8, 9, 11, 13 e 15 e a Trincheira 2 (Figura 02 e Tabela 01) podem ser classificados como Cambissolos progredindo para organização de horizonte $\mathrm{Bw}$, correspondendo à passagem do substrato sedimentar siltito-arenito ao material de origem cristalina (granito e/ou quartzito).

Já em relação aos pontos 7, 10 e 12 e à Trincheira 3 (Figura 02 e Tabela 01), devido à pequena espessura, à cor, à textura e à relação $\mathrm{S} / \mathrm{A}$, configura-se o domínio de Cambissolos típicos, embora possam ocorrer condições eutróficas originadas de cultivos locais. Tais solos encontram-se no terço inferior das vertentes, sobre substrato cristalino. 
TABELA 01. Resultados das amostras de solo dos pontos 1 a 15. Legenda: os pontos foram analisados de acordo com profundidade (P.), cor, textura (Text.), relação silte/argila (S/A) e saturação em bases (V\%). $a$ = argilosa; $f$-a = franco-argilosa; $f$-ar. $=$ franco-arenosa; $f$ = franca; $f$-a-s $=$ franco-argilo-siltosa; f-a-ar. = franco-argilo-arenosa; a-s = argilo-siltosa; ar.-f = areia franca.

\begin{tabular}{|c|c|c|c|c|c|c|c|c|}
\hline PT & P. & COR & ARG. (\%) & AREIA (\%) & SILTE (\%) & TEXT. & S/A & V (\%) \\
\hline \multirow{10}{*}{01} & 10 & 5 YR $3 / 3$ & 33,75 & 37,5 & 28,75 & $f-a$ & 0,85 & 64 \\
\hline & 20 & $5 \mathrm{YR} 3 / 3$ & 35,97 & 35,6 & 28,43 & $f-a$ & 0,79 & 68 \\
\hline & 30 & 5 YR $3 / 3$ & 35,9 & 36,5 & 27,6 & $f-a$ & 0,77 & 68 \\
\hline & 40 & 2.5 YR $3 / 6$ & 35,47 & 36,1 & 28,43 & $f-a$ & 0,8 & 68 \\
\hline & 50 & 2.5 YR $3 / 6$ & 36,95 & 35,2 & 27,85 & $f-a$ & 0,75 & 64 \\
\hline & 60 & 2.5 YR 4/4 & 38,25 & 33,6 & 28,15 & $f-a$ & 0,74 & 66 \\
\hline & 70 & 2.5 YR $3 / 6$ & 36,25 & 31,95 & 31,8 & $f-a$ & 0,88 & 63 \\
\hline & 80 & 2.5 YR 4/6 & 39,85 & 34,8 & 25,35 & $f-a$ & 0,64 & 59 \\
\hline & 90 & 2.5 YR 5/6 & 41,1 & 33,32 & 25,58 & $f-a$ & 0,62 & 45 \\
\hline & 100 & 2.5 YR 4/6 & 42,8 & 35,57 & 21,64 & $f-a$ & 0,51 & 54 \\
\hline \multirow{10}{*}{02} & 10 & 5 YR 4/4 & 34 & 27,45 & 38,55 & $f-a$ & 1,13 & 64 \\
\hline & 20 & 5 YR 4/4 & 28 & 34,45 & 37,55 & $f-a$ & 1,34 & 65 \\
\hline & 30 & 2.5 YR 4/6 & 27,25 & 32,65 & 40,1 & $f-a$ & 1,47 & 66 \\
\hline & 40 & 2.5 YR 4/6 & 31,25 & 28,55 & 40,2 & $f-a$ & 1,29 & 58 \\
\hline & 50 & 2.5 YR 4/8 & 46,25 & 27,25 & 26,5 & a & 0,57 & 55 \\
\hline & 60 & 2.5 YR 4/8 & 34,25 & 26,75 & 39 & $f-a$ & 1,14 & 59 \\
\hline & 70 & 2.5 YR 4/8 & 33,75 & 26,7 & 39,55 & $f-a$ & 1,17 & 49 \\
\hline & 80 & 2.5 YR 4/8 & 39,75 & 26,6 & 33,65 & $f-a$ & 0,85 & 53 \\
\hline & 90 & 2.5 YR 4/8 & 38,75 & 27 & 34,25 & $f-a$ & 0,88 & 52 \\
\hline & 100 & 2.5 YR 4/8 & 38,25 & 27,6 & 34,15 & $f-a$ & 0,89 & 51 \\
\hline \multirow{10}{*}{03} & 10 & 5 YR $3 / 3$ & 40,37 & 34,67 & 24,96 & $f-a$ & 0,62 & 68 \\
\hline & 20 & 2.5 YR $3 / 3$ & 36,05 & 34,11 & 29,84 & $f-a$ & 0,83 & 66 \\
\hline & 30 & 2.5 YR $3 / 4$ & 38,1 & 30,67 & 31,23 & $f-a$ & 0,82 & 65 \\
\hline & 40 & 2.5 YR 3/4 & 50,5 & 29,25 & 20,25 & $\mathrm{a}$ & 0,4 & 62 \\
\hline & 50 & 2.5 YR 3/4 & 44,37 & 29,35 & 26,27 & $a$ & 0,59 & 64 \\
\hline & 60 & $2.5 \mathrm{YR}$ & 42,72 & 30,95 & 26,33 & $a$ & 0,62 & 67 \\
\hline & 70 & 2.5 YR $3 / 4$ & 44,55 & 30,2 & 25,25 & $a$ & 0,57 & 66 \\
\hline & 80 & 2.5 YR $3 / 4$ & 45,57 & 30,6 & 23,83 & $a$ & 0,52 & 64 \\
\hline & 90 & $2.5 \mathrm{YR}$ & 44,15 & 31,23 & 24,62 & $a$ & 0,56 & 56 \\
\hline & 100 & $2.5 Y R$ & 44,07 & 31,54 & 24,39 & $a$ & 0,55 & 38 \\
\hline \multirow{10}{*}{04} & 10 & 7,5 YR $3 / 3$ & 19,37 & 57,06 & 23,56 & $f$ & 1,22 & 66 \\
\hline & 20 & 7,5 YR $3 / 3$ & 16 & 60,45 & 23,55 & f-ar & 1,47 & 66 \\
\hline & 30 & 7,5 YR 4/4 & 19 & 57,8 & 23,2 & f-ar & 1,22 & 67 \\
\hline & 40 & 7,5 YR 4/4 & 19,47 & 53,44 & 27,08 & $f$ & 1,39 & 63 \\
\hline & 50 & 7,5 YR 4/4 & 47,3 & 24,7 & 28 & $\mathrm{a}$ & 0,59 & 64 \\
\hline & 60 & 7,5 YR 4/6 & 38,72 & 32,54 & 28,74 & $f-a$ & 0,74 & 62 \\
\hline & 70 & 7,5 YR 4/6 & 18,2 & 44,03 & 37,77 & $f$ & 2,08 & 60 \\
\hline & 80 & 5 YR 4/6 & 18,97 & 42,19 & 38,83 & $f$ & 2,05 & 58 \\
\hline & 90 & 5 YR 4/6 & 15,05 & 44,17 & 40,78 & $f$ & 2,71 & 55 \\
\hline & 100 & 5 YR 5/6 & 19,5 & 44,05 & 36,45 & $f$ & 1,87 & 44 \\
\hline \multirow{10}{*}{05} & 10 & 7.5 YR 4/2 & 39,75 & 30,55 & 29,7 & $f-a$ & 0,75 & 23 \\
\hline & 20 & 7.5 YR 5/1 & 32,5 & 27,7 & 39,8 & $f-a$ & 1,22 & 7 \\
\hline & 30 & 7.5 YR $6 / 1$ & 39,75 & 32,35 & 27,9 & $f-a$ & 0,7 & 14 \\
\hline & 40 & 7.5 YR 6/1 & 41,5 & 33,1 & 25,4 & $a$ & 0,61 & 14 \\
\hline & 50 & 2.5 YR $8 / 6$ & 36 & 25,95 & 38,05 & f-a-s & 1,06 & 6 \\
\hline & 60 & 2.5 YR $8 / 6$ & 13,75 & 65,55 & 20,7 & f-ar & 1,51 & 6 \\
\hline & 70 & 2.5 YR $6 / 8$ & 22 & 59,8 & 18,2 & f-a-ar & 0,83 & 2 \\
\hline & 80 & 7.5 YR $6 / 8$ & 26,5 & 60,2 & 13,3 & f-a-ar & 0,5 & 3 \\
\hline & 90 & 7.5 YR 6/8 & 22 & 61,2 & 16,8 & $f$-a-ar & 0,76 & 3 \\
\hline & 100 & 7.5 YR 6/8 & 24 & 59,1 & 16,9 & f-a-ar & 0,7 & 2 \\
\hline
\end{tabular}




\begin{tabular}{|c|c|c|c|c|c|c|c|c|}
\hline PT & P. & COR & ARG. (\%) & AREIA (\%) & SILTE (\%) & TEXT. & S/A & V (\%) \\
\hline \multirow{10}{*}{06} & 10 & 10 YR 4/2 & 10,25 & 76,6 & 13,15 & f-ar & 1,28 & - \\
\hline & 20 & 10 YR 4/2 & 11,5 & 76,35 & 12,15 & f-ar & 1,06 & - \\
\hline & 30 & 10 YR 4/3 & 13 & 74 & 13 & f-ar & 1 & - \\
\hline & 40 & 10 YR 4/4 & 16,75 & 71,95 & 11,3 & f-ar & 0,67 & - \\
\hline & 50 & 10 YR 4/4 & 19,25 & 68,8 & 11,95 & f-ar & 0,62 & - \\
\hline & 60 & 10 YR 4/4 & 22 & 66,25 & 11,75 & f-a-ar & 0,53 & - \\
\hline & 70 & 10 YR 5/6 & 20 & 67,6 & 12,4 & f-a-ar & 0,62 & - \\
\hline & 80 & 7.5 YR 4/6 & 21,5 & 66,5 & 12 & f-a-ar & 0,56 & - \\
\hline & 90 & 7.5 YR 5/6 & 20 & 68,4 & 11,6 & f-a-ar & 0,58 & - \\
\hline & 100 & 7.5 YR 5/6 & 21,5 & 67,85 & 10,65 & f-a-ar & 0,5 & - \\
\hline \multirow{10}{*}{07} & 10 & 5 YR $3 / 3$ & 37,5 & 32,2 & 30,3 & $f-a$ & 0,81 & - \\
\hline & 20 & 5 YR $3 / 3$ & 42,5 & 26,7 & 30,8 & a & 0,72 & - \\
\hline & 30 & 5 YR 3/4 & 40,75 & 29,6 & 29,65 & $a$ & 0,73 & - \\
\hline & 40 & 10 YR $5 / 2$ & 22,25 & 56,75 & 21 & f-a-ar & 0,94 & - \\
\hline & 50 & 10 YR 5/8 & 21 & 58,75 & 20,25 & f-a-ar & 0,96 & - \\
\hline & 60 & 10 YR 5/8 & 24,75 & 45,3 & 29,95 & $f$ & 1,21 & - \\
\hline & 70 & 10 YR $6 / 4$ & 34,75 & 37,45 & 27,8 & $f-a$ & 0,8 & - \\
\hline & 80 & 10 YR 3/6 & 33,75 & 38,8 & 27,45 & $f-a$ & 0,81 & - \\
\hline & 90 & 10 YR 5/6 & 31,27 & 43,12 & 25,61 & $f-a$ & 0,82 & - \\
\hline & 100 & 10 YR 5/8 & 28,27 & 47,86 & 23,87 & f-a-ar & 0,84 & - \\
\hline \multirow{10}{*}{08} & 10 & 7.5 YR 3/2 & 15 & 72,95 & 12,05 & f-ar & 0,8 & - \\
\hline & 20 & 7.5 YR $3 / 2$ & 15 & 65,85 & 19,15 & f-ar & 1,28 & - \\
\hline & 30 & 7.5 YR 3/2 & 17,5 & 63,35 & 19,15 & f-ar & 1,09 & - \\
\hline & 40 & 7.5 YR $3 / 2$ & 17,5 & 62,4 & 20,1 & f-ar & 1,15 & - \\
\hline & 50 & 7.5 YR $3 / 2$ & 22,5 & 60,45 & 17,05 & $f$-a-ar & 0,76 & - \\
\hline & 60 & 7.5 YR $3 / 3$ & 20,25 & 62,85 & 16,9 & f-a-ar & 0,83 & - \\
\hline & 70 & 7.5 YR $3 / 3$ & 21,75 & 61,75 & 16,5 & f-a-ar & 0,76 & - \\
\hline & 80 & 7.5 YR 3/4 & 20,52 & 66,14 & 13,33 & f-a-ar & 0,65 & - \\
\hline & 90 & 7.5 YR 4/4 & 21,75 & 65,6 & 12,65 & f-a-ar & 0,58 & - \\
\hline & 100 & 7.5 YR 4/4 & 21,5 & 40,45 & 38,05 & $\mathrm{~F}$ & 1,77 & - \\
\hline \multirow{10}{*}{09} & 10 & 5 YR 4/2 & 31,57 & 44,88 & 23,54 & $f-a$ & 0,75 & - \\
\hline & 20 & 5 YR 4/2 & 27,02 & 49,21 & 23,77 & $f-a$ & 0,88 & - \\
\hline & 30 & 5 YR 4/4 & 28,93 & 46,28 & 24,8 & $f-a$ & 0,86 & - \\
\hline & 40 & 5 YR 4/6 & 31,15 & 47,04 & 21,81 & $f-a$ & 0,7 & - \\
\hline & 50 & 5 YR 4/6 & 33,82 & 43,42 & 22,76 & $f-a$ & 0,67 & - \\
\hline & 60 & 5 YR 4/6 & 29,75 & 43,2 & 27,05 & $f-a$ & 0,91 & - \\
\hline & 70 & 5 YR 4/6 & 28,25 & 43,2 & 28,55 & $f-a$ & 1,01 & - \\
\hline & 80 & 5 YR 4/6 & 28 & 43,85 & 28,15 & $f-a$ & 1,01 & - \\
\hline & 90 & 5 YR 4/6 & 27,75 & 44,9 & 27,35 & $f-a$ & 0,99 & - \\
\hline & 100 & 5 YR 4/6 & 32,5 & 42,85 & 24,65 & $f-a$ & 0,76 & - \\
\hline \multirow{10}{*}{10} & 10 & 7.5 YR $3 / 2$ & 7,75 & 65,8 & 26,45 & f-ar & 3,41 & - \\
\hline & 20 & 7.5 YR 3/2 & 7,5 & 68,35 & 24,15 & f-ar & 3,22 & - \\
\hline & 30 & 7.5 YR 3/2 & 9,5 & 67,4 & 23,1 & $\mathrm{f}$-ar & 2,43 & - \\
\hline & 40 & 7.5 YR $3 / 3$ & 8,75 & 68,9 & 22,35 & f-ar & 2,55 & - \\
\hline & 50 & 7.5 YR $3 / 3$ & 9,25 & 69,25 & 21,5 & f-ar & 2,32 & - \\
\hline & 60 & 7.5 YR 3/4 & 15,25 & 64,3 & 20,45 & f-ar & 1,34 & - \\
\hline & 70 & 7.5 YR 3/4 & 17,75 & 63,1 & 19,15 & f-ar & 1,08 & - \\
\hline & 80 & 5 YR 4/6 & 16,07 & 66,32 & 17,61 & f-ar & 1,1 & - \\
\hline & 90 & 5 YR 4/6 & 19,75 & 58,25 & 22 & f-ar & 1,11 & - \\
\hline & 100 & 5 YR 4/6 & 19,75 & 59,7 & 20,55 & f-ar & 1,04 & - \\
\hline \multirow{6}{*}{11} & 10 & 5 YR $3 / 3$ & 10,75 & 64 & 25,25 & f-ar & 1,03 & - \\
\hline & 20 & 5 YR $3 / 3$ & 11,25 & 64,25 & 24,5 & f-ar & 0,91 & - \\
\hline & 30 & 5 YR $3 / 3$ & 14,5 & 61,75 & 23,75 & f-ar & 1,25 & - \\
\hline & 40 & 5 YR $3 / 3$ & 12,5 & 62,3 & 25,2 & f-ar & 1,24 & - \\
\hline & 50 & 5 YR 4/3 & 11,25 & 64,7 & 24,05 & f-ar & 0,87 & - \\
\hline & 60 & 5 YR 4/4 & 11,82 & 66,66 & 21,51 & f-ar & 0,75 & - \\
\hline
\end{tabular}




\begin{tabular}{|c|c|c|c|c|c|c|c|c|}
\hline PT & P. & COR & ARG. (\%) & AREIA (\%) & SILTE (\%) & TEXT. & S/A & V (\%) \\
\hline & 70 & 5 YR 4/4 & 9,77 & 69,21 & 21,01 & f-ar & 0,95 & - \\
\hline & 80 & 5 YR 4/4 & 9,57 & 68,67 & 21,76 & $f$-ar & 1,14 & - \\
\hline & 90 & 5 YR 4/4 & 12,42 & 67,6 & 19,98 & f-ar & 1,1 & - \\
\hline & 100 & 5 YR 4/4 & 11,42 & 71,83 & 16,75 & $f$-ar & 0,92 & - \\
\hline \multirow{10}{*}{12} & 10 & $7.5 \mathrm{YR}$ & 10,75 & 64 & 25,25 & $f$-ar & 2,35 & - \\
\hline & 20 & 7.5 YR 3/4 & 11,25 & 64,25 & 24,5 & $f$-ar & 2,18 & - \\
\hline & 30 & 5 YR $3 / 4$ & 14,5 & 61,75 & 23,75 & f-ar & 1,64 & - \\
\hline & 40 & 5 YR 3/4 & 12,5 & 62,3 & 25,2 & f-ar & 2,02 & - \\
\hline & 50 & 5 YR 4/4 & 11,25 & 64,7 & 24,05 & $f$-ar & 2,14 & - \\
\hline & 60 & 5 YR 4/6 & 11,82 & 66,66 & 21,51 & f-ar & 1,82 & - \\
\hline & 70 & 5 YR 4/6 & 9,77 & 69,21 & 21,01 & $f$-ar & 2,15 & - \\
\hline & 80 & 5 YR 4/6 & 9,57 & 68,67 & 21,76 & $f$-ar & 2,27 & - \\
\hline & 90 & 5 YR 4/6 & 12,42 & 67,6 & 19,98 & f-ar & 1,61 & - \\
\hline & 100 & 5 YR 4/6 & 11,42 & 71,83 & 16,75 & f-ar & 1,47 & - \\
\hline
\end{tabular}

\begin{tabular}{|c|c|c|c|c|c|c|c|c|}
\hline \multirow{10}{*}{13} & 10 & 5 YR $3 / 3$ & 48,5 & 16,95 & 34,55 & $a-s$ & 0,71 & - \\
\hline & 20 & 5 YR 3/3 & 45 & 16,75 & 38,25 & $a-s$ & 0,85 & - \\
\hline & 30 & 5 YR 3/4 & 44,25 & 17,4 & 38,35 & $a-s$ & 0,87 & - \\
\hline & 40 & 5 YR 3/4 & 46,75 & 17,2 & 36,05 & $a-s$ & 0,77 & - \\
\hline & 50 & 2.5 YR $3 / 4$ & 45 & 17,3 & 37,7 & $a-s$ & 0,84 & - \\
\hline & 60 & 2.5 YR $3 / 6$ & 44,75 & 16,45 & 38,8 & $a-s$ & 0,87 & - \\
\hline & 70 & 2.5 YR 4/6 & 45,25 & 19,7 & 35,05 & $a-s$ & 0,77 & - \\
\hline & 80 & 2.5 YR 4/6 & 53,5 & 17,65 & 28,85 & $a-s$ & 0,54 & - \\
\hline & 90 & 2.5 YR 4/6 & 40,75 & 15,55 & 43,7 & $a-s$ & 1,07 & - \\
\hline & 100 & 2.5 YR 4/6 & 52,5 & 18,35 & 29,15 & $a-s$ & 0,56 & - \\
\hline \multirow{10}{*}{14} & 10 & $10 \mathrm{R} 3 / 3$ & 40,25 & 22,2 & 37,55 & $a$ & 0,93 & - \\
\hline & 20 & $10 \mathrm{R} 3 / 3$ & 46 & 19,85 & 34,15 & $a$ & 0,74 & - \\
\hline & 30 & 10 R $3 / 3$ & 44,25 & 19,15 & 36,6 & $a$ & 0,83 & - \\
\hline & 40 & 10 R 3/4 & 46 & 18,35 & 35,65 & a & 0,77 & - \\
\hline & 50 & 10 R 3/4 & 52,25 & 18,5 & 29,25 & a & 0,56 & - \\
\hline & 60 & 10 R 3/4 & 47,25 & 18,6 & 34,15 & a & 0,72 & - \\
\hline & 70 & 10 R 3/4 & 56,75 & 18,15 & 25,1 & a & 0,44 & - \\
\hline & 80 & 10 R $3 / 4$ & 57,75 & 18,2 & 24,05 & a & 0,42 & - \\
\hline & 90 & 10 R 3/4 & 52,25 & 18,55 & 29,2 & $a$ & 0,56 & - \\
\hline & 100 & 10 R 3/4 & 59,5 & 17,15 & 23,35 & a & 0,39 & - \\
\hline \multirow{10}{*}{15} & 10 & 7,5 YR 3/3 & 9,75 & 80,19 & 10,06 & ar. $-f$ & 1,03 & - \\
\hline & 20 & 7,5 YR 3/4 & 10,58 & 80,86 & 8,56 & ar. $-f$ & 0,81 & - \\
\hline & 30 & 7,5 YR 4/4 & 10,15 & 80,87 & 8,98 & ar. - $f$ & 0,88 & - \\
\hline & 40 & 7,5 YR 4/4 & 10,23 & 80,36 & 9,41 & ar. - f & 0,92 & - \\
\hline & 50 & 7,5 YR 4/3 & 17,28 & 75,06 & 7,66 & f-ar & 0,44 & - \\
\hline & 60 & 7,5 YR 4/3 & 13,8 & 77,09 & 9,11 & f-ar & 0,66 & - \\
\hline & 70 & 7,5 YR 4/4 & 15,02 & 74,91 & 10,06 & $f-a r$ & 0,67 & - \\
\hline & 80 & 7,5 YR 4/4 & 18,9 & 73,49 & 7,61 & $f-a r$ & 0,4 & - \\
\hline & 90 & 7,5 YR 4/6 & 20,1 & 72,11 & 7,79 & f-ar & 0,39 & - \\
\hline & 100 & 7,5 YR 4/6 & 21,47 & 72,02 & 6,5 & f-ar & 0,3 & - \\
\hline \multirow{10}{*}{16} & 10 & 10 YR 3/6 & 19,5 & 54,4 & 26,1 & f-ar & 1,34 & 69 \\
\hline & 20 & 10 YR $3 / 4$ & 20,75 & 50,35 & 28,9 & $f$-ar & 1,39 & 77 \\
\hline & 30 & 7,5 YR 4/4 & 25,25 & 48,8 & 25,95 & $f$ & 1,03 & 74 \\
\hline & 40 & 7,5 YR 4/4 & 23,42 & 53,65 & 22,93 & f-a-ar & 0,98 & 72 \\
\hline & 50 & 7,5 YR 5/6 & 26,25 & 49,45 & 24,3 & $f$ & 0,93 & 67 \\
\hline & 60 & 7,5 YR 5/6 & 28,5 & 47,8 & 23,7 & $f$ & 0,83 & 67 \\
\hline & 70 & 7,5 YR 5/6 & 28,5 & 46,65 & 24,85 & $f$ & 0,87 & 63 \\
\hline & 80 & 7,5 YR 4/6 & 34,25 & 43,85 & 21,9 & $f-a$ & 0,64 & 61 \\
\hline & 90 & 7,5 YR 5/6 & 31 & 42,05 & 26,95 & $f-a$ & 0,87 & 49 \\
\hline & 100 & 7,5 YR 5/6 & 31,75 & 44,35 & 23,9 & $f-a$ & 0,75 & 32 \\
\hline
\end{tabular}

Fonte: Elaborado pelos autores. 
Apesar de não haverem sido feitas coletas, análises de laboratório ou análises morfológicas dos solos no fundo de vale do campus, a análise de amostras coletadas com trado comprovou a condição de hidromorfia e a proximidade do lençol freático, implicando em condições de gleização na planície fluvial (Santos et al., 2013). Portanto, nessa e nas partes mais inferiores dos vales fluviais foram constatadas condições morfológicas de hidromorfia. Com isso, tais áreas indicam o domínio de Gleissolos.

Dessa maneira, o entendimento dos aspectos do meio físico, norteados pela cartografia morfopedológica, permitiu constatar que o relevo é condicionado ao substrato geológico e responde aos compartimentos de determinadas altimetrias, declividades e morfologias associadas. Os solos refletem essa interação a partir das condições morfográficas, da exposição dos materiais do substrato e dos dados obtidos nos pontos de coleta (Tabela 01). Logo, foi possível determinar quatro unidades morfopedológicas na área de pesquisa (Figura 03).
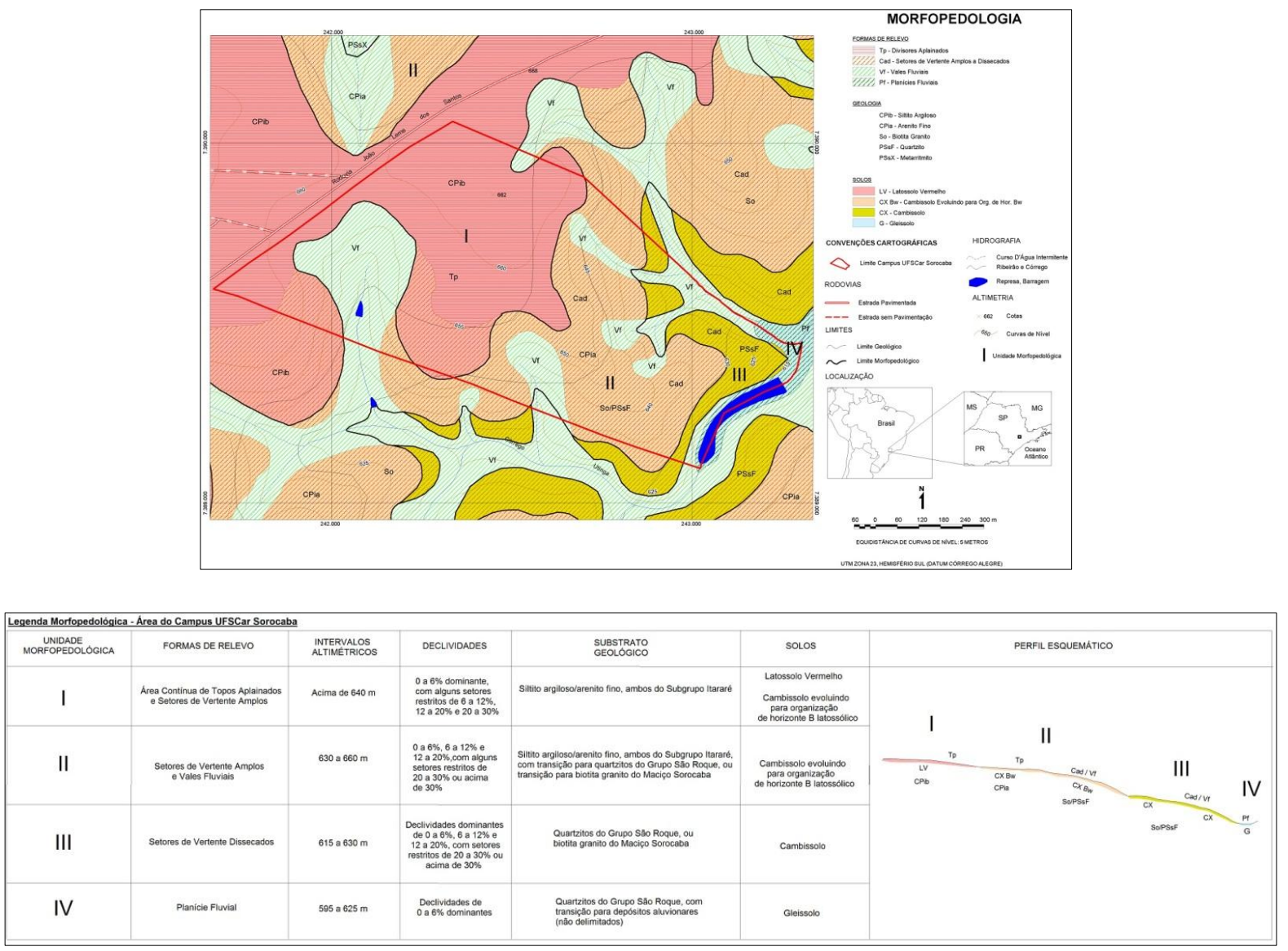

FIGURA 03: Mapa morfopedológico.

Fonte: Elaborado pelos autores.

No zoneamento para a ocupação, foram definidas quatro unidades (Figura 04) a partir da análise integrada entre os mapas de morfopedologia e de uso atual da terra. Para tanto, considerou-se como prioridade as características do meio físico, as áreas de cabeceira de drenagem e as áreas topograficamente favoráveis à implantação de construções do campus universitário e do entorno. 
A Área de Ocupação (Figura 04) perfaz aproximadamente 40,63 dos 70 ha do campus, e é caracterizada pela topografia propícia para sítio de ocupação principal. A Área de Ocupação Moderada, com aproximadamente 2,08 ha do campus, corresponde aos trechos a oeste, que envolvem setores de contribuição dos respectivos córregos, possuindo remanescentes de matas secundárias que acompanham as drenagens.

Em ambas as áreas podem ser encontradas pequenas sobreposições, em razão dos contatos entre as delimitações. Desse modo, entende-se que a Área de Ocupação Moderada representa a transição entre a Área de Ocupação e a área seguinte, classificada como Área Restrita à Ocupação. Com quase 27,3 ha, esta corresponde a algumas áreas de nascente, que envolvem setores côncavos de vertente, associadas aos polígonos de vegetação secundária existente. As matas ciliares que circundam as drenagens são envolvidas por áreas de plantio ou possuem, nas proximidades, barreiras naturais de vegetação.

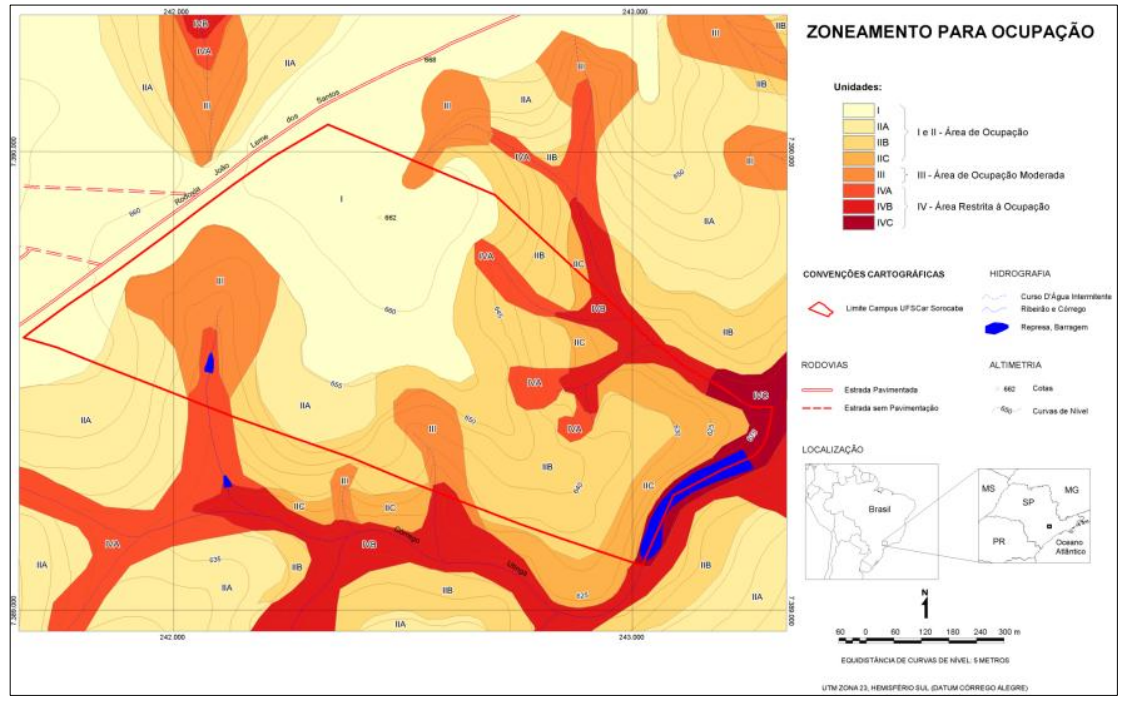

FIGURA 04: Zoneamento para ocupação.

Fonte: Elaborado pelos autores.

\section{DISCUSSÃO}

A metodologia adotada - configurada como análise integrada de mapas temáticos produzidos em gabinete, com dados levantados em campo e análises de laboratório provou ser eficiente na constatação de características do meio físico pertinentes à compartimentação morfopedológica, objetivo principal deste trabalho.

Nas áreas de vertentes mais íngremes, o substrato caracteriza-se pela passagem do sedimentar para o cristalino, com a existência de Cambissolos. No entanto, na transição da área de topos aplainados para os setores amplos a dissecados, não se percebe de imediato a razão dos solos serem pouco desenvolvidos, visto que recobrem superfícies de declividade baixa, sem mudanças bruscas no relevo, embora haja espessamento do horizonte Bi e a morfologia indique sua evolução para Bw.

Portanto, a distribuição das unidades sofre grande influência da geologia, especialmente se for considerada a ocorrência dos granitos, pois estes configuram corpo batolítico de grande extensão. A configuração deles como Maciço influenciaria na pedogênese por se diferenciar 
da cobertura sedimentar, caracterizando superfície basal em contraposição à camada sobrejacente, altamente intemperizada.

A ocorrência do granito pode ser responsável pela acumulação de água na camada sobrejacente, tornando-a suscetível a processos erosivos, o que explicaria a ocorrência de solos pouco desenvolvidos. Ainda foram encontrados afloramentos de granito com minerais pouco alterados na área dos divisores aplainados, indicando que a exumação desses batólitos pode ser recente.

O relevo caracteriza modelado aplainado em antiga superfície geomórfica, com maior dissecação para o fundo de vale, que transita do domínio do substrato sedimentar para o cristalino. Nele a formação dos solos parece estar associada às formas de relevo e às mudanças do substrato geológico, que respondem pela formação de solos maduros com horizontes B latossólicos no domínio sedimentar de áreas de topos aplainados, e pela organização pedológica em processo de formação de horizontes Bw na transição sedimentar - cristalino, em setores de vertente amplos e de formação de horizontes Bi no domínio cristalino, em área mais dissecada.

O zoneamento aplicado ao levantamento morfopedológico evidencia que a ocupação das cabeceiras de drenagem ou das áreas de contribuição hídrica próximas a essas podem influenciar na diminuição da disponibilidade d'água, comprometendo a vazão dos córregos e o escoamento subsuperficial nos solos, o que consequentemente prejudicaria o desenvolvimento da vegetação. Na década de 60, várias das cabeceiras aqui referidas apresentavam voçorocas ou ravinas, e, atualmente, estas se encontram preenchidas por sedimentos, com vegetação secundária à volta. A ocupação dessas áreas tenderia a assorear ainda mais as drenagens intermitentes, prejudicando o volume de água à jusante.

Embora seja designada como Área de Ocupação no zoneamento, a superfície aplainada com Latossolos Vermelhos profundos e desenvolvidos deve ser conservada, por representar uma extensa superfície de absorção de água, com eficiente controle sobre a vazão do sistema de drenagem. A impermeabilização progressiva dessa superfície decorrente da implantação de novas edificações poderá resultar na formação de excedentes hídricos, capazes de desencadear significativos processos erosivos nos solos incipientes das vertentes e concorrer para o assoreamento das planícies fluviais.

\section{CONCLUSÃO}

O levantamento morfopedológico executado, voltado à aptidão do meio físico e uso e ocupação, demonstrou a integração dos fatores levantados que configuram a paisagem existente no campus universitário da UFSCar.

Pôde ser constatada mudança de solos aliada às transições morfológicas e geológicas, evidenciando um sistema de transformação da cobertura pedológica ao longo da vertente, seguindo a área do campus universitário do topo ao fundo de vale. A aplicação deste levantamento ao zoneamento priorizou a conservação de áreas cuja classificação envolve partes não só das cabeceiras de drenagem, como também da planície fluvial. 
Tais unidades tornam-se mais suscetíveis às intervenções antrópicas que, por ventura, venham a acontecer caso sejam ocupadas ou modificadas, devendo ser conservadas em seus aspectos estruturais e funcionais.

\section{AGRADECIMENTOS}

Os autores agradecem ao Programa Institucional de Bolsas de Iniciação Científica (PIBIC) do Conselho Nacional de Desenvolvimento Científico e Tecnológico (CNPQ) pela bolsa concedida.

\section{BIBLIOGRAFIA}

AEROCARTA S.A. Levantamento para a Prefeitura Municipal de Sorocaba. Faixa de Vôo 10. Sorocaba, 2006. Escala 1:20.000.

ALMEIDA, F. F. M.; HASUI, Y.; PONÇANO, W. L.; DANTAS, A. S. L; CARNEIRO, C. D. R.; MELO, M. S. e BISTRICHI, C. A. Mapa Geológico do Estado de São Paulo . São Paulo, IPT, n. 1184, 1981. 2 v.. Escala 1:500.000. (Monografias 6).

BASE AEROFOTOGRAMETRIA E PROJETOS S. A. Projeto IAC Região 7 - Foto 3003. Sorocaba, Terra Foto, 1962a. Escala Aproximada 1:25.000.

BASE AeROfOtOgrametriA E PROJetOS S. A. Projeto IAC Região 7 - Foto 3004. Sorocaba, Terra Foto, 1962b. Escala Aproximada 1:25.000.

CASTRO, S.S; SALOMÃO, F. X. T. Compartimentação morfopedológica e sua aplicação: Considerações Metodológicas. Geousp, 7:27-37, 2000.

DE BIASI, M. A carta clinográfica: os métodos de representação e sua confeç̧ão. RDG, 6:4560, 1992.

GODOY, A.M. Caracterização faciológica, petrográfica e geoquímica dos maciços Sorocaba e São Francisco. São Paulo, Universidade de São Paulo, 1989. 220p. (Tese de Doutorado).

INSTITUTO BRASILEIRO DE GEOGRAFIA E ESTATístICA - IBGE. Manual técnico de pedologia. 2.ed. Rio de Janeiro, 2007. 316p.

INSTITUTO DE PESQUISAS TECNOLÓGICAS - IPT. Relatório Técnico no 91265 - 205. Plano de Bacia da Unidade de Gerenciamento dos Recursos Hídricos do Sorocaba e Médio Tietê. Relatório Final. São Paulo, 2006. 153 p.

INSTITUTO GEOGRÁFICO E CARTOGRÁFICO - IGC. Folha Bairro Utinga - SF-23-Y-C- IV-2-NE-F. São Paulo, 1979a. Escala 1:10.000.

INSTITUTO GEOGRÁFICO E CARTOGRÁFICO - IGC . Folha Fazenda São Marcos - SF- 23-Y-C-IV2-NE-D. São Paulo, 1979b. Escala 1:10.000.

LIBAULT, A. Geocartografia. 1a ed. São Paulo, Ed. Nacional/EDUSP, 1975.

ROSS, J.L.S.; MOROZ, I.C. Mapa Geomorfológico do Estado de São Paulo. São Paulo, DGFFLCH-USP/IPT/Fapesp, 1997. 2 v. Escala 1:500.000. 
SANTOS, H. G.; JACOMINE, P. K. T.; ANJOS, L. H. C.; OLIVEIRA, V. A.; LUMBRERAS, J. F.; COELHO, M. R.; ALMEIDA, J. A.; CUNHA, T. J. F.; OLIVEIRA, J. B. Sistema brasileiro de classificação de solos. 3. ed. Brasília, DF: Embrapa, 2013. 353 p.

SILVA, P.C.F. Ambientes de sedimentação e tectônica do Grupo São Roque na região entre Pilar do Sul e Votorantim, SP. São Paulo, Universidade de São Paulo, 1997. 127p. (Dissertação de Mestrado).

TRICART, J.; KILIAN, J. La Eco-Geografia y la ordenación del medio natural. 2a ed. Barcelona, Editorial Anagrama, 1982.

Artigo submetido em

Artigo aceito em
$09 / 11 / 2015$

$21 / 10 / 2015$ 